\title{
THE CHEMISTRY AND PHYSICS OF NONLINEAR OPTICAL MATERIALS: A NEW LOOK AT AN OLD FIELD
}

\section{STEPHAN P. VELSKO and DAVID EIMERL}

Lawrence Livermore National Laboratory, P.O. Box 5508, L-490, Livermore, CA 94550

Recent efforts to "engineer" new nonlinear optical materials with specific desired characteristics has engendered a need for a theoretical description of optical properties which is readily accessible to chemists, yet correctly treats the essential physics of dielectric response. This paper describes a simple empirical molecular orbital model which gives useful insights into the relationship between chemical composition, crystalline structure, and optical susceptibilities. We compare the probabilities of finding new harmonic generators in various chemical classes. Rigorous bounds on the magnitudes of linear and nonlinear optical coefficients and their anisotropies are also discussed.

* Work performed under the auspices of the U. S. Department of Energy by the Lawrence Livermore National Laboratory under contract number W-7405-ENG-48. 